\title{
Using Big Data in Learning Organizations
}

\author{
Desi Tri Widyaningrum \\ Faculty of Computer Science, Trinity College Dublin \\ Dublin, Ireland \\ widyanid@tcd.ie
}

\begin{abstract}
Nowadays, Learning Organizations should consider big data as a strategic business asset. The benefits of big data analysis include increased cost efficiency, revenue growth, and competitive value in the market. Indeed, company leaders have to adapt to the need for rapid change. Companies such as Amazon and Nike have proven the importance of using big data to support predictive and decision-making behaviors. It also affects the organization aspects such as strategy, people, structure, rewards, and process. It is not intended to deal with every element of the organization, but to explore the relevant relationships between big data and the learning process. This article highlights the way in which big data affects an organization's success through the use of adequate analytics. The essay begins with an introduction to the characteristics of Learning Organizations as a great model for companies. The next section reviews definitions of big data and explores the emergence of big data as a trend in recent years. The following section discusses the implementation of big data in Learning Organizations. Finally, the essay concludes by revisiting some of the main issues presented.
\end{abstract}

Keywords- Big Data, Learning Organization, Profit Growth, Analytics, Business strategies

\section{INTRODUCTION}

Shorter product cycles, global competition, and increased workplace differences are the factors that have triggered companies to adapt faster to challenging conditions [1]. Company leaders need to articulate a clear vision and develop their organizations as Learning Organizations so that they can win among their competitors [2].

As companies see their competitors use information for competitive advantage, technology will play an important role in historical valuation. While following technological developments is fairly easy, understanding how information bring value as an organizational resource is more challenging. Companies should treat big data as an asset and involve information strategists and IS professionals in its management, as well as developing standards for data governance and professional ethics for data uses [3].

The big data revolution has precipitated rapid changes in business [4]. Companies have seized the opportunities of big data for storing, aggregating, and cultivating expanding forms of information. For example, Galbraith [5] showed how Nike, Inc. created new business strategies by incorporating the analytical and decision-making capabilities of big data. They gather information from community management and develop new products based on ongoing dialogs with their customers. In addition, they use information gleaned from big data analysis to continuously update their supply chain management [5]. Big data is not only speeding up the decision-making process, it is also dramatically altering realtime product advertising. Berner, Graupner, and Maedche [6] also emphasized how big data's facilitation of information visibility can assist employees' empowerment. This shift will influence how organizational structures should be arranged to maximize opportunities and benefits.

In order to implement big data in Learning Organizations, Senge [7] defined Learning Organizations as "Organizations where people continually expand their capacity to create the results they truly desire, where new and expansive patterns of thinking are nurtured, where collective aspiration is set free and where people are continually learning how to learn together". He also described the dimensional aspects to establishing learning skills, namely the following: Systems Thinking, Personal Mastery, Mental Model, Shared Vision, and Team Learning. Establishing these capabilities will help organizations cultivate tolerance and build interactive discussions with holistic perspectives. Thus, this paper will highlight big data implementation and benefit in Learning Organization.

\section{LEARNING ORGANIZATIONS AND BIG DATA CHARACTERISTICS}

\section{A. Five main abilities of Learning Organization}

Garvin [8] finds that learning in companies is related to how they receive knowledge and enhance their performance. Successful companies, such as Honda and General Electrics, are adept at transforming the knowledge of their workforce and manage learning processes by adequate planning rather than reacting after the fact [8]. He also derived five main abilities that Learning Organizations (LO) should have, which are as follows:

- Systematic problem solving; LOs should manage organizational issues using the scientific method and insist on data. Rather than guesswork and assumptions, they should use statistical tools to support decisionmaking.

- Experimentation with new approaches; Parallel to systematic problem solving, LOs should also expand the new approach of learning. Continuous improvement should be encouraged to ensure a steady flow of new ideas, especially those that increase productivity and decrease costs.

- Learning from their own experience and past history; Records of experiences should be assessed and reviewed as lessons for companies and their 
employees. Successes and failures are valuable lessons learned that could be used for establishing new approaches and solutions when companies want to improve their products or services.

- Learning from the experiences and best practices of others; In addition to learning from their own experiences, new perspectives from the outside environment could help strengthen ideas and critical thinking. Effective methods, such as Benchmarking and customer conversation, accelerate the process of learning from others.

- Transferring knowledge quickly and efficiently throughout the organization; Knowledge and learning resources must be shared effectively and efficiently throughout a company.

Transferring knowledge manually, such as training and employee rotation, are good for some circumstances. However, technology can also help because electronic sources will speed up the learning capability of the entire organization.

In order to achieve these skills, Marquardt [9] claimed that Information Technology plays a considerable role in the workplace and on the learning processes of workers. Using technology to scan and observe the business climate might enable a proactive approach to fierce world changes [9]. In addition, technology also establishes performance-support systems and can be used for information discovery and data mining. In the end, companies and their employees could benefit from Technology-Based Learning, such as computerbased Training. Obviously, technology simply does a more efficient and effective job.

\section{B. Seven dimensional of Big Data}

Minelli, Chambers, and Dhiraj [10] defined big data as the "Next generation of Data Warehousing and Business Analytics". Bharadwaj, El Sawy, Pavlou, and Venkatraman [11] highlighted the social influence of big data as media channels employ it. Relatedly, Smith [12] emphasized the urgent importance of businesses investing in information that is extracted from social media platforms and CRM analytics. Due to its ability to facilitate real-time responses to customer requests, companies should prioritize their investment in increasing the speed of information flows.

According to Minelli, Chambers, \& Dhiraj [10], there are three dimensions around big data which are Volume, Variety and Velocity. First, Volume is measured by quantity of transactions and events. By exploring data volume, companies could target accuracy increasing of predictive models. Second, Variety nowadays related to complex unstructured data source such as Internet data, research, location, image etc. Third, velocity covered on the pace of data is produced, acquired, absorbed and processed [10].

In addition, Van Rijmenam [13] added four more dimensions - the four Vs - Veracity, Variability, Visualization, and Value. The fourth dimension, Veracity, emphasizes the need for automated data to be correct in order to support accurate analysis and decision-making. Noise and abnormality in data should not distract from the analytical process's ability to produce meaningful information. The fifth dimension, Variability, is related to analyzing variability among the same type of data. For example, many different types of apples are sold in one store. Variability focuses on how the taste and size of each apple differs even when they are all of the same variety. This is variability in apples, and it also applies to data. The sixth dimension, Visualization, helps people understand complex results. Without a good understanding of the data, the information that it produces is useless; visualizing data allows people to "see" rather than simply read about the results. Finally, Value is the component that is produced after data is analyzed and turned into further information, knowledge, and wisdom. Analyzing data according to these dimensions supports decision-making processes and assists companies in maintain their competitiveness.

Furthermore, Masie [14] suggested that big data is beneficial for LOs. Big data offers clear competitive advantages from the data that are successfully processed and analyzed. Precise interventions based on empirical research better support better companies' decision-making than interventions based on experience and instinct [6]. For example, Amazon surpassed its competition by using big data analysis better understand their customers' purchasing needs and to predict what their customers might want to purchase next [3].

Indeed, big data affects firm performance by enabling data-driven decision-making. Therefore, recent additional analytics have emerged to establish a new scale of information visibility [6]. This new scale alters not only strategic, but also operational, decisions. Berner, Graupner, and Maedche [6] illustrated this change in their comparison of the Smart Machine Era and the Big Data Era. In the Smart Machine Era, information systems created organizational processes automation and produced new information by visualizing activities, events, and objects. Meanwhile, in the Big Data Era, information systems become more valuable that could supportrapid business decisions making. The complete comparison is shown in Table 1 [6]. 
TABLE I. COMPARISON OF PAST AND FUTURE INFORMATION VISIBILITY

\begin{tabular}{|l|l|l|}
\hline \multicolumn{1}{|c|}{ Characteristic } & Smart Machine Era & \multicolumn{1}{c|}{ Big Data Era } \\
\hline $\begin{array}{l}\text { Information } \\
\text { Timeliness }\end{array}$ & Historical data & Real-time data \\
\hline $\begin{array}{l}\text { Information } \\
\text { Sources }\end{array}$ & $\begin{array}{l}\text { Self-created, high } \\
\text { quality datasets }\end{array}$ & $\begin{array}{l}\text { Large amount of data } \\
\text { including unreliable external } \\
\text { datasets }\end{array}$ \\
\hline $\begin{array}{l}\text { Information } \\
\text { Reach }\end{array}$ & Strategic level & $\begin{array}{l}\text { Strategic and operational } \\
\text { levels }\end{array}$ \\
\hline $\begin{array}{l}\text { Information } \\
\text { Relevance for } \\
\text { Decision Making }\end{array}$ & $\begin{array}{l}\text { Low (experience- } \\
\text { driven decision } \\
\text { making) }\end{array}$ & $\begin{array}{l}\text { High (data-driven decision } \\
\text { making) }\end{array}$ \\
\hline
\end{tabular}

On the other hand, as shown in Fig. 1., big data is a continuation of the ERP, CRM, and e-Commerce eras [10]; [5] proposed that big data should be organized like other assets, such as talent and money, in HR and Finance departments. This claim is based on the fact that the management of vast amounts of data supports the automation of CRM and eCommerce management. The data processing is a thousand times faster and processes millions of records with a full individual profile. Focusing on the role of big data will help organizations make better business decisions [3].

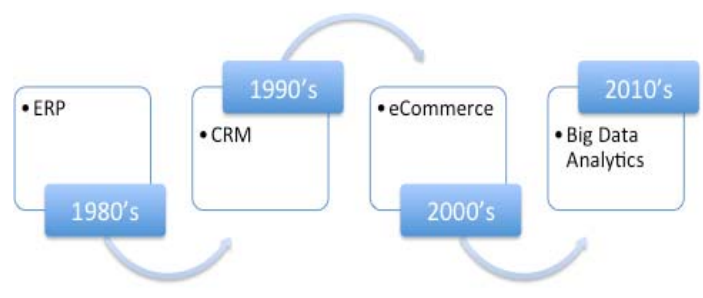

Fig. 1. Timeline of Recent Technology Developments

\section{IMPLEMENTATIONS}

\section{A. Learning Organizations and Big Data Relations}

Learning from experience and history is a part of Learning Organizations, the investment and collaboration among people, processes, and technology should be in line with current technology trends [8]. In contrast, Minelli, Chambers, \& Dhiraj [10] contended that history has no narration or objectives. Big data professionals should be capable of aligning technical issues with business goals. Otherwise, synchronizing would be unbeneficial when it does not fit into current business goal.

In a complete analysis, as previously mentioned in LOs characteristics by Garvin [8], there are five aspects covered by big data trends. The descriptions are as shown in Table 2 [4] :
TABLE II. COMPARISON OF LOS AND BIG DATA

\begin{tabular}{|c|c|}
\hline $\begin{array}{c}\text { LO Characteristics } \\
{[8]}\end{array}$ & Big Data Influence \\
\hline $\begin{array}{l}\text { Systematic problem } \\
\text { solving }\end{array}$ & $\begin{array}{l}\text { Big data offer precise interventions based on } \\
\text { empirical research to support decision- } \\
\text { making. For example: Amazon is leading in } \\
\text { understanding customer need [3] }\end{array}$ \\
\hline $\begin{array}{l}\text { Experimentation } \\
\text { with new approaches }\end{array}$ & $\begin{array}{l}\text { Big data enable new ideas, that enhance } \\
\text { productivity and reduce expenses. For } \\
\text { example: RTI launched CRM tools to } \\
\text { engage with customer by social media [4] }\end{array}$ \\
\hline $\begin{array}{l}\text { Learning from their } \\
\text { own experience and } \\
\text { past history }\end{array}$ & $\begin{array}{l}\text { Big data recorded Successes and failures as } \\
\text { lessons learned in products and services } \\
\text { improvements. For example, LinkedIn and } \\
\text { eBay have agile software development } \\
\text { process that continuously gives feedback } \\
\text { based on users' experiences [5] }\end{array}$ \\
\hline $\begin{array}{l}\text { Learning from the } \\
\text { experiences and best } \\
\text { practices of others }\end{array}$ & $\begin{array}{l}\text { Effective methods, such as Benchmarking } \\
\text { and customer conversation, accelerate the } \\
\text { process of learning from others. Big data } \\
\text { enables product development by } \\
\text { Benchmarking to other companies. For } \\
\text { examples: Nike, General Electric and } \\
\text { Bosch put sensors in their products. With } \\
\text { the GPS features, Nike can develop } \\
\text { additional applications that bring Nike in the } \\
\text { software business. [5] }\end{array}$ \\
\hline $\begin{array}{l}\text { Transferring } \\
\text { knowledge quickly } \\
\text { and efficiently } \\
\text { throughout the } \\
\text { organization }\end{array}$ & $\begin{array}{l}\text { Big data enables effective collection, storage } \\
\text { and transfer of knowledge. For examples: } \\
\text { Credit Suisse uses Web-based Learning, } \\
\text { CBT as a knowledge transfer system. The } \\
\text { marketing can also analyze customer needs } \\
\text { by Learning Management System [9] }\end{array}$ \\
\hline
\end{tabular}

\section{B. Impacts of Big Data in Learning Organizations}

Despite its rapid change, big data has significant influence on company major elements [5]. The impacts are illustrated as the star model in the Fig. 2. below in the elements of strategy, people, structure, rewards and process [5]:

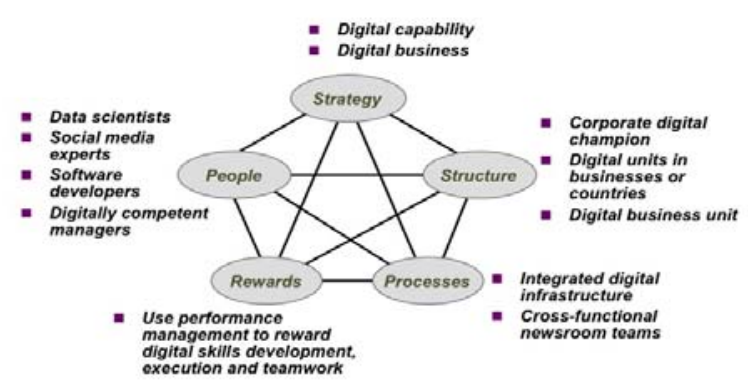

Fig. 2. Big Data's Impact on the Organization 
From the strategy perspective, LOs need to establish strategy for big data implementation [5]. First, digital capability in supporting decision-making and improve the product. For instance, Disney expands its service by allowing people to watch any program through Cable Company and any device. Their objective is to get revenue from advertising on Disney channel. Second, digital business insights would enable new profit center from customer custom report. Bosch, in the electrical component supplier, is an example the process of analyzing data from anti-rollover software and other system become safety and maintenance guidance for customer [5]. As an adaptive organization, LOs could transform the capabilities and business insights align with business achievement [9].

From the perspective of other elements, Organization should adapt to the trend. HR takes important role in conducting big data analysis [10]. HR should prepare the think-tank team and design the learning processes to align with the framework. Because people are part of the equation, there are three areas with which they should be concerned, which are as follows [9]; [5]:

- Organizational alignment / Structure; LOs continuously map out business objectives and business processes that adapt to fast changing conditions. The digital units become an urgent part of LOs to win the competitive circumstances.

- Executive endorsement and sponsorship /Processes and Rewards; LOs appraise learner, especially for quality, delivery and innovation in the product company to increase revenue.

- Investing in analytical human capital /People; By the proper measurement in LOs, learning processes become a trigger for employee continuously transfer their knowledge both from internal and external sources. Furthermore, HR would put more attention to the need of new experts such as data scientist and Digital Manager.

This framework is similar to that proposed by Grossman and Siegel [15] which is the CSPG (Culture, Staffing, Processes and Governance) Framework for analytics. The summary of the CSPG framework and the correlation with Minelli, Chambers, \& Dhiraj [10] are as shown in Table 3:

TABLE III. COMPARISON OF CSPG AND MINELLI,CHAMBERS AND DHIRAJ APPROACH

\begin{tabular}{|l|l|l|}
\hline $\begin{array}{c}\text { Analytics } \\
\text { Dimension } \\
\text { (CSPG) }\end{array}$ & \multicolumn{1}{|c|}{ analytics } & \multicolumn{1}{|c|}{$\begin{array}{c}\text { Minelli, Chambers } \\
\text { and Dhiraj } \\
\text { Approach }\end{array}$} \\
\hline $\begin{array}{l}\text { Analytics } \\
\text { Culture }\end{array}$ & $\begin{array}{l}\text { Big Data should be integrated into } \\
\text { corporate strategy }\end{array}$ & $\begin{array}{l}\text { Organizational } \\
\text { Alignment }\end{array}$ \\
\hline $\begin{array}{l}\text { Analytics } \\
\text { Staff }\end{array}$ & $\begin{array}{l}\text { Big data should be analyzed by } \\
\text { talented team member in the right } \\
\text { department }\end{array}$ & $\begin{array}{l}\text { Investing in } \\
\text { analytical human } \\
\text { capital }\end{array}$ \\
\hline $\begin{array}{l}\text { Analytics } \\
\text { Processes }\end{array}$ & $\begin{array}{l}\text { Big data should be built, deployed } \\
\text { and provided valuable analytics } \\
\text { output for business. }\end{array}$ & $\begin{array}{l}\text { Executive } \\
\text { endorsement and } \\
\text { sponsorship }\end{array}$ \\
\hline
\end{tabular}

As a result, big data business models would bring benefits as follow [10]:

- Big data would enhance efficiencies in operational by decreasing risks and expense, saving time, simplifying the complex process and facilitate self-service.

- Big data also enable profit growth by sell to micro trends, enhance customer involvement and access to detect fraud.

- Big data also differentiate business with Competitive value by providing innovative service, grab market share and incubating investment.

\section{SUMMARY}

In conclusion, there is a wealth of research on big data implementation benefit to the organization, and it has been referred as suited tools for Learning Organizations to achieve its goal. Researchers have shown that big data creates competitive value for the business environment. This essay has addressed the important relationship between LOs and Big data and some impacts that have to be considered.

The issues that have not been covered are dimensional of big data. Veracity, as one of them, plays an important role in producing trustable analytics. With the continuous improvement in data selection, Learning Organizations would maximize its profit in the future.

\section{References}

[1] S. Goh, \& G. Richards, "Benchmarking the Learning Capability of Organizations", European Management Journal, Vol. 15, No. 5, 1997, pp.575-583,

[2] D. A. Garvin, A. C. Edmonson, \& F. Gino (2008), "Is Yours a Learning Organization?", Harvard Business Review 86, no. 3, 2008, pp. 109-116, Retrieved June 28, 2015, from Harvard Business Review: https://hbr.org/2008/03/is-yours-a-learning-organization

[3] S. Miller, "Collaborative Approaches Needed to Close the Big Data Skills Gap", Journal of Organization Design, 3(1), 2014, pp.26-30.

[4] T. J. Gabel, \& C. Tokarski, "Big Data and Organization Design; Key Challenges Await the Survey Research Firm", Journal of Organization Design , 3(1), 2014, pp.37-55.

[5] J.R. Galbraith, "Organization Design Challenges Resulting From Big Data", Journal of Organization Design, 3(1), 2014, pp. 2-13.

[6] M. Berner, E. Graupner, \& A. Maedche, "The Information Panapticon in the Big Data Era", Journal of Organization Design, 3(1), 2014, pp.14-19.

[7] P.M. Senge, The Fifth Discipline, The Art and Practice of the Learning Organisation, London: Random House Publishing Group, Inc., 2006, ISBN: 978-1-905-21120-3.

[8] D. A.Garvin, "Building a Learning Organization", Harvard Business Review 71, no. 4 (July-August 1993), pp. 78-91, Retrieved 16 25, 2015 , from Harvard Business Review: https://hbr.org/1993/07/building-alearning-organization

[9] M. J. Marquardt, Building the Learning Organization; Achieving Strategic Advantage through a Commitment to Learning. Boston: Nicholas Brealey Publishing, 2011, ISBN 978-1-857-88926-0.

[10] M. Minelli, M. Chambers \& A. Dhiraj, Big Data, Big Analytics, Emerging Business Inteligence and Analytic Trends for Today's Businesses, New Jersey: John Wiley \& Sons, Inc., 2013, ISBN 978-1118-14760-3. 
[11] A. Bharadwaj, O. A. El Sawy, P. A. Pavlou \& N. Venkatraman, "Digital Business Strategy: Toward a Next Generation of Insights", MIS Quarterly, Vol. 37 No. 2, 2013, pp. 471-482.

[12] G. S. Smith, Straight to the Top : CIO Leadership in a Monile, Social and Cloud-based World (2nd ed.), New Jersey: John Wiley \& Sons, Inc., 2013, ISBN 978-1-118-39003-0.
[13] M. van Rijmenam, Think Bigger; Developing a Successful Big Data Strategy for Your Business, New York: Amacom Books, 2014, ISBN 978-0-814-43415-4.

[14] E. Masie, Big Learning Data. Alexandria, VA, USA: ASTD Press, 2014, ISBN 978-1-56286-909-0.

[15] R. L. Grossman, \& K. P. Siegel, "Organizational Models for Big Data and Analytics”, Journal of Organization Design , 3(1), 2014, pp. 20-25. 